\title{
EDUCAÇÃO AMBIENTAL NA EDUCAÇÃO DE JOVENS E ADULTOS: UMA CONEXÃO NECESSÁRIA PARA A CONSTRUÇÃO DA CIDADANIA
}

\section{Silvana Heloísa Ferreira Cruz ${ }^{1}$}

\section{Alôncio de Oliveira²}

RESUMO: O presente artigo aborda a Educação Ambiental na Educação de Jovens e Adultos como possibilidade para a formação da cidadania. Trata-se de um estudo descritivo baseado em estudos já publicados e em literatura específica da área. Destaca a metodologia de Paulo Freire no processo da alfabetização de Adultos, enfatiza as seguintes categorias: dialocidade, ética, participação, conscientização e libertação. Aponta para o uso de metodologias interdisciplinares para a prática de educação ambiental na Educação de Jovens e Adultos. Apresenta como um bom exemplo de metodologia interdisciplinar "As Toadas do Boi-Bumbá de Parintins" como possibilidades para se trabalhar a sustentabilidade ambiental começando a partir da realidade local. Reflete sobre as políticas públicas da Educação de Jovens e Adultos, considera que esta modalidade de ensino precisa de investimentos para a formação de professores, sobretudo no que tange as metodologias específicas voltadas a essa modalidade de ensino.

Palavras-chave: Educação Ambiental. Educação de Jovens e Adultos. Cidadania.

\footnotetext{
${ }^{1}$ Pedagoga do Centro de Ciências do Ambiente da Universidade Federal do Amazonas - UFAM. Mestre em Educação pela Faculdade de Educação da Universidade Federal do Amazonas - FACED - UFAM. Doutoranda em Ciências da Educação pela Universidade de Trás-os-Montes e Alto Douro - UTAD, Vila Real, Portugal. silvanaheloisa@ufam.edu.br

${ }^{2}$ Técnico em Assuntos Educacionais do Centro de Ciências do Ambiente da Universidade Federal do Amazonas UFAM.

Mestrando em Educação pela Faculdade de Educação da Universidade Federal do Amazonas - FACED - UFAM. oliveiraloncio@yahoo.com.br
} 


\section{INTRODUÇÃO}

A Educação de Jovens e Adultos de acordo com a Lei de Diretrizes e Bases da Educação Nacional - LDBNE - № 9394/96 "é uma modalidade da educação básica nas etapas do ensino fundamental e médio" (Souza e Silva, 1997:63), tem uma clientela específica, a sua maioria é composta por alunos trabalhadores maiores de quinze anos ou mais de idade.

Muitos desses alunos pertencem à classe social de baixo poder aquisitivo e possivelmente moram em áreas vulneráveis aos riscos ambientais.

A história das pessoas jovens e adultas é marcada por lutas constantes por pessoas engajadas em movimentos populares sociais que exercem forte pressão política ao poder dominante para fazer valer o seu direito à educação. Muitas das vezes esses resultados são marcados por avanços e retrocessos, dependendo do contexto sóciohistórico em estão inseridos.

O direito à educação aos indivíduos que compõem a sociedade brasileira, especificamente as pessoas jovens e adultas, mesmo sendo garantido na Constituição Federal - CF/1988, na LDBEN - №9394/96, assegurado no Parecer CNE/CEB no 11/2000, muitos dessas pessoas tiveram esse direito negado por muito tempo, pois não tiveram acesso ao ensino na idade regular configurando-se em um grande contingente de analfabetos.

O Brasil, segundo Censo de 2012 do IBGE publicado pela (Veja/2012) possui quase 14 milhões de pessoas maiores de 15 ou mais de idade que não sabem ler e escrever.

No sentido de resolver o problema do analfabetismo no Brasil, e tentar reparar esta dívida social, o governo brasileiro vem se esforçando através de suas políticas públicas para garantir o acesso e a permanência dos alunos na escola, especificamente para aqueles que não tiveram acesso à escola na idade regular.

Nesse sentido, ao se trabalhar os processos mais elementares de ensino, iniciando pela alfabetização de adultos, os professores da EJA poderão adotar a 
metodologia de Paulo Freire, que tem como essência o respeito pelo ser humano, seu paradigma de educação entre outras ideias, preconiza uma educação libertadora, livre da alienação, da exploração, trabalhar em prol da emancipação, isto possivelmente será possível através da palavra, da leitura de mundo e do conhecimento. Ao se referir sobre essa questão Freire apud Boff (2012:250) diz:

Os 'analfabetos' são analfabetos de escrita, e não de oralidade, e a leitura do mundo precede a leitura da palavra" (Freire. Pedagogia da esperança, p.236). O livro da vida é o grande livro em que todos podem ler e aprender. Somente depois vem o livro escrito, que tenta recolher e redizer o livro da vida.

A educação é uma forma de intervenção no mundo, no sentido de mudá-lo. Educador e educando, juntos, aprendem na troca de saberes e de experiências que unidos, podem contribuir a construção do inédito viável (expressão cunhada por ele), que é aquele sonho possível de ser antecipado, a realização de uma ideia geradora que chegou a seu amadurecimento e que por isso ninguém pode calá-la; enfim, o irromper de um mundo novo no qual não seja tão difícil amar e ser gente.

Assim sendo, no método de Paulo Freire, as palavras geradoras utilizadas pelo professor no processo de aprendizagem devem partir do cotidiano dos alunos, em seguidas serão contextualizadas com a turma até que se chegue ao conhecimento cabal do objeto. A metodologia freireana utiliza algumas categorias como: conscientização, dialocidade, eticidade, participação, politização, autonomia, libertação entre outras.

Um ponto importante a ser destacado por Paulo Freire é que educar é um processo político libertador. "Ao aprender a ler e a contar o estudante aprende a entender o mundo em que vive e sofre. O primeiro ato de libertação consiste na conquista da palavra; ele deixa de ser um silenciado," (Freire apud Boff, 2013:247).

Nesse sentido, o professor deve estabelecer uma relação de respeito com os alunos, deve promover o diálogo, iniciando o seu trabalho pedagógico pelo contexto real dos alunos, a sala de aula deve ser um local propício para a aprendizagem, o círculo é um recurso a ser utilizado, pois estabelece um nivelamento entre professor e aluno, aqui não há hierarquia, todos sabem, a aprendizagem acontece através da troca de experiências, à 
medida que o professor ensina, ele também aprende com seu aluno. "A razão ética da abertura, seu fundamento político, sua referência pedagógica; a boniteza que há nela como viabilidade do diálogo". (Freire, 2011:133)

Nesse sentido, é na prática do diálogo, no saber escutar e se comunicar com o outro é que se desvenda a realidade, esta pode ser transformada ou não. $O$ aluno ao chegar à escola já traz consigo uma bagagem cultural são saberes construídos na prática comunitária. A escola, especificamente o professor devem respeitar os saberes dos educandos, o grande desafio reside em saber articulares os saberes, ou seja, o saber que o aluno traz consigo para a escola, produto de suas relações histórico-culturais com o conhecimento a ser ensinado.

Freire (2011:31/32) diz:

Ensinar exige respeito aos saberes dos educandos.

[...] Por que não aproveitar a experiência que têm os alunos de viver em áreas da cidade descuidadas pelo poder público para discutir, por exemplo, a poluição.

"Dos riachos e dos córregos e os baixos níveis de bem-estar das populações, os lixões e os riscos que oferecem à saúde das gentes.

Tais questões são fulcrais para os questionamentos relacionados à problemática ambiental, porque conduzem os alunos a problematizarem a situação vivenciada, algumas perguntas devem ser questionadas como: Esta situação está assim, por quê? Quem são os responsáveis pelos danos causados à natureza e suas consequências socioambientais? O que devemos fazer para reverter tais impactos? Essas e outras questões devem ser discutidas, analisadas, dialogadas em grupo com a participação de todos os atores sociais envolvidos. É possível dizer que somente com o compromisso e o envolvimento do grupo, possa ser possível encontrar respostas e soluções para tais questões.

A Educação Ambiental e a Educação de Jovens e Adultos podem ser aliadas no processo de ensino-aprendizagem, uma vez que seus objetos de ensino versam sobre justiça social, cidadania planetária, ética, sustentabilidade, educação de qualidade um 
direito para todos os cidadãos que devem ser garantidos nas políticas públicas de educação do estado brasileiro.

\section{AS FUNÇÕES DA EDUCAÇÃO DE JOVENS E ADULTOS}

As diretrizes da Educação de Jovens e Adultos (2000) preconizam três funções da EJA, a saber: função reparadora, função equalizadora e função qualificadora.

De modo bem sucinto podemos dizer o significado de cada função de acordo com As Diretrizes da Educação de Jovens e Adultos (2000:7) como:

A primeira função reparadora, significa não só a entrada no circuito dos direitos civis pela restauração de um direito negado: um direito a uma escola de qualidade, mas também o reconhecimento daquela igualdade ontológica de todo e qualquer ser humano.

A função equalizadora da EJA vai dar cobertura a trabalhadores e a tantos outros segmentos sociais como donas de casa, migrantes, aposentados e encarcerados. A reentrada no sistema educacional dos que tiveram uma interrupção forçada seja pela repetência ou pela evasão, seja pelas desiguais oportunidades de permanência ou outras condições adversas, deve ser saudada como reparação corretiva, ainda que tardia, de estruturas arcaicas, possibilitando aos indivíduos novas inserções no mundo do trabalho, na vida social, nos espaços da estética e na abertura dos canais de participação.

A terceira função é a qualificadora tem como objetivo propiciar a todos a atualização de conhecimentos por toda a vida é a função permanente da EJA. Ela tem como o caráter incompleto do ser humano cujo potencial de desenvolvimento e de adequação pode se atualizar em quadros escolares ou não escolares. "Mais do que nunca, ela é um apelo para a educação permanente e criação de uma sociedade educada para o universalismo, a solidariedade, a igualdade e a diversidade.

Para cumprir tais funções da EJA são necessários entre outros aspectos, políticas públicas de formação para professores, para que os mesmos possam trabalhar com metodologias específicas para essa clientela escolar. A EJA tem uma identidade própria, específica, exige-se uma aplicação de metodologias voltadas para esse público, nesse 
aspecto é possível dizer que a legislação educacional já assegura esse direito, pois as Diretrizes Curriculares Nacionais para a Educação de Jovens e Adultos em seu Art. 5ำ preconizam: "Os componentes curriculares consequentes ao modelo pedagógico próprio da educação de jovens e adultos e expressos nas propostas pedagógicas das unidades educacionais [...]" (Resolução CNE/CEB № 1 de 2000).

Podemos dizer com base em estudos descritivos e de acordo com em nossas experiências no magistério, que há evasão e repetência nessa modalidade de ensino do ensino fundamental, no turno noturno, muito significativo, isto talvez dentre outros aspectos, esteja relacionada ao uso não apropriado de metodologias específicas para esta modalidade de ensino, carecendo investimentos por parte do poder público para sanar esta lacuna.

Considerando o grande número de pessoas quase 14 milhões de pessoas jovens e adultas brasileiras maiores de quinze anos de idade que ainda não sabem ler e escrever e para atender essa demanda, uma possibilidade é adotar metodologias eficazes que possam ser desenvolvidas em sala de aula.

\section{CONSIDERAÇÕES ACERCA DO MÉTODO DE PAULO FREIRE NA EDUCAÇÃO DE JOVENS E ADULTOS}

Com base na história da educação brasileira é possível dizer que o método de Paulo Freire obteve grande êxito quando fora aplicado nas escolas públicas brasileiras, porém teve pouca duração, pois suas ideias eram avançadas para a época.

A sua metodologia de trabalho tem como pressupostos básicos: o diálogo, a política, a liberdade e a conscientização. O pensamento freireano, parte da ideia de educar o homem para ser mais, ser sujeito de seu conhecimento, ser sujeito autônomo, pois acreditava que de posse de seu conhecimento, o sujeito poderia se libertar da opressão e da alienação e isso só é possível através da educação, só a educação tem o poder de mudar e ou de transformar. O professor deve sempre em sua prática pedagógica utilizar o diálogo, pois é no saber comunicar-se com o outro, no saber escutar é que reside a grande descoberta da realidade e assim, professor, professora, aluno e aluna juntos irão construindo e reconstruindo seus saberes. Reforçando essa ideia sobre 
o diálogo na educação, Freire (2011:112) afirma que "Não há também diálogo se não há uma intensa fé nos homens. Fé no seu poder de fazer e de refazer. De criar e recriar. Fé na sua vocação de ser mais, que não é privilégio de alguns eleitos, mas direito dos homens".

De forma bem sucinta apresentaremos um breve histórico do pensamento de Paulo Freire e sua importância para a educação brasileira, sobretudo para a educação de pessoas jovens e adultas no processo de alfabetização.

Paulo Freire não propôs um método entre outros. Antes de fazer isso ele investiu aos brados com uma educação, contra outras.

No modelo de educação positivista o conhecimento é transmitido pelo professor ao aluno desprovido de seu mundo real, produzindo um sujeito passivo e alienado.

É contra esse modelo de ensino autoritário, antidemocrático e elitista que Freire lutou e combateu. Nesse contexto, construiu um paradigma educacional que tem como premissa básica a educação para a libertação, inicialmente seu trabalho pedagógico objetivava ensinar os adultos trabalhadores no processo de alfabetização.

Ao prefaciar a obra Pedagogia do Oprimido de Paulo Freire (1987:13), o Professor Ernani Maria Fiori coloca:

Paulo Freire é um pensador comprometido com a vida: não pensa ideias, pensa a existência.

[...] O método Paulo Freire não ensina a repetir palavras, não se restringe a desenvolver a capacidade de pensá-las segundo as exigências lógicas do discurso abstrato; simplesmente coloca o alfabetizando em condições de poder reexistenciar criticamente as palavras de seu mundo, para na oportunidade devida, saber dizer a sua palavra.

[...] Com a palavra, o homem se faz homem. Ao dizer a sua palavra, pois, o homem assume conscientemente sua essencial condição humana. "E o método que the propicia essa aprendizagem comensura-se ao homem todo, e seus princípios fundam toda pedagogia, desde a sua alfabetização até os mais altos níveis do labor universitário.

A sua metodologia de ensino reside nas seguintes categorias: ética, conscientização, participação, diálogo, politização, criticidade e libertação. 
“Um dos pressupostos do método é a ideia de que ninguém educa ninguém e ninguém se educa sozinho. A educação, que deve ser um ato coletivo, solidário - um ato de amor, dá para pensar sem susto - não pode ser imposta”. (Brandão, s/d)

Na prática pedagógica professores, alunos e monitores devem fazer um círculo de cultura, pois todos devem se postar como iguais, no mesmo nível, não há hierarquia. $\mathrm{O}$ conhecimento parte da realidade do grupo, assim sendo vão sendo construídas as palavras geradoras, em outra fase posterior os temas geradores.

As palavras geradoras não precisam ser muitas. De 16 a 23 é o bastante. Em uma experiência para uma comunidade em Cajueiro Seco, no Recife, nos anos 60, a equipe escolheu as seguintes: tijolo, voto, siri, palha, biscate, cinza, doença, chafariz, máquina, emprego, engenho, mangue, terra, enxada, classe.

É obvio que estas palavras codificam o modo de vida das pessoas dos lugares onde a "descoberta" foi feita. Para serem decodificadas num outro momento de descoberta, o do círculo de cultura, a cada palavra foi associada um núcleo de questões, ao mesmo tempo existenciais (ligadas à vida) e políticas (ligadas aos determinantes sociais das condições de vida).

À medida que as etapas forem sendo superada, a proposta de trabalho com o método vai se ampliando, assim, esta etapa de codificação das descobertas continua na escolha de temas geradores. Geralmente acontece quando a etapa de alfabetização é prolongada na de pós-alfabetização.

O método de alfabetização que Paulo Freire "pensou funciona de tal sorte que realiza, dentro do círculo de cultura, a prática do diálogo que o sonho do educador imagina um dia existir no círculo do mundo, entre todos os homens [...]" (Brandão, s/d).

Paulo Freire nos deixou um grande legado importante para a educação brasileira e mundial, as suas ideias eram revolucionárias para a época, pois se contrapunham a qualquer tipo de exploração e opressão dada aos trabalhadores, se indignava com a desigualdade social construída por um modelo capitalista de natureza predatória e excludente.

A sua luta era em favor da vida, da existência humana, defendia o diálogo nas relações humanas. Acreditava no sonho, defendia a educação para a libertação, pois só 
assim seria possível a transformação social. "No mundo da história, e da cultura, da política, constato não para me adaptar, mas para mudar" (Freire, 2011:75).

\section{METODOLOGIAS INTERDISCIPLINARES DE EDUCAÇÃO AMBIENTAL NA EDUCAÇÃO DE JOVENS E ADULTOS PARA A FORMAÇÃO DA CIDADANIA}

A educação ambiental pode ser compreendida como uma prática educativa voltada para as resoluções dos problemas socioambientais. Nesse sentido trabalha em prol da solidariedade entre os povos e das pessoas, da justiça social, combate a sociedade de consumo e o sistema econômico capitalista responsável pela degradação ambiental e seus impactos negativos para a sociedade.

A educação ambiental busca entre outros aspectos, segundo o Art. $3^{\circ}$ das diretrizes curriculares nacionais para a educação ambiental (2012) assim, expressa:

A Educação Ambiental visa à construção de conhecimentos, ao desenvolvimento de habilidades, atitudes e valores sociais, ao cuidado com a comunidade de vida, a justiça e a equidade socioambiental e a proteção do meio ambiente natural e construído.

A escola é um local para se disseminar conhecimentos que favoreçam a construção de tais preceitos, isto implica trabalhar as questões ambientais de forma crítica, os temas geradores devem estar de acordo com a realidade do aluno, pois assim, poderão intervir na realidade. É na participação e na interação com os outros que serão construídos caminhos para a formação da cidadania e, cabe à escola formar o cidadão.

A Educação de Jovens e Adultos por possuir uma identidade própria e ter uma clientela específica, pois a sua maioria é composta de pessoas trabalhadoras, cujos mesmos já têm uma vivência, então, é perfeitamente possível e necessário utilizar metodologias interdisciplinares para se trabalhar temas ambientais. 
De forma bem sucinta podemos dizer que a interdisciplinaridade pode ser compreendida como um diálogo entre as diversas disciplinas para se chegar a uma visão da totalidade.

O conhecimento obtido nas escolas ainda se encontra marcado pelo paradigma cartesiano produzindo uma visão parcial e fragmentada do conhecimento. É notório perceber esta fragmentação no currículo escolar, as disciplinas são compartimentadas, separadas, parece que não nenhuma relação entre elas.

Então, a interdisciplinaridade surge como um paradigma emergente do conhecimento, pois é preciso entender o mundo na sua totalidade.

O princípio interdisciplinar pode ser entendido, segundo Fazenda (2013:20) como:

[...] o pensar interdisciplinar parte do princípio de que nenhuma forma de conhecimento é em si mesma racional. Tenta, pois, o diálogo com outras formas de conhecimento, deixando-se interpenetrar por elas. Assim, por exemplo, aceita o conhecimento do senso comum como válido, pois é através do cotidiano que damos sentido às nossas vidas. Ampliado através do diálogo com o conhecimento científico, tende a uma dimensão utópica e libertadora, pois permite enriquecer nossa relação com o outro e com o mundo.

Para que ocorra o diálogo entre as diversas disciplinas são necessárias à utilização de metodologias interdisciplinares no ensino, nesse sentido, na EJA pode-se trabalhar a temática ambiental de forma integrada e interdisciplinar em atividades que envolvam: músicas ecológicas, pinturas, artesanatos, poemas, poesias, desenhos, leituras, etc.

Vale ressaltar que quaisquer atividades trabalhadas com os alunos em sala de aula, deverão estar relacionadas à realidade do aluno para que os mesmos possam fazer o exercício da ação-reflexão e assim poderem encontrar as respostas para as mesmas.

Em nossa realidade amazônica, encontramos na música regional, um verdadeiro tesouro a ser trabalhado para o despertar e formação do sujeito ecológico. As toadas dos bois bumbás de Parintins, representam verdadeiros hinos ecológicos, pois exaltam a defesa da vida em todas as suas formas. Também servem como gritos de denúncias sobre as agressões que o homem causa à natureza e seus efeitos negativos ao meio ambiente. 
Importa registrar que o folclore de Parintins representado na Festa do Boi-Bumbá de Parintins objetiva divulgar e difundir a arte e a cultura popular do homem amazônida que vive na região norte do Brasil. Utiliza o ambiente amazônico como cenário para desvendar e retratar o modo de vida do caboclo e sua relação com a natureza. Salientase que partir da Rio/92, as toadas do boi-bumbá de Parintins passaram a enfocar temas ecológicos voltados para a preservação ambiental da Amazônia.

Temos um pequeno fragmento da toada "À arte do audacioso", autoria de Paulinho Du Sagrado, do Boi Caprichoso (2011) que expressa:

\section{“[...] Amazônia sublime, Amazônia divina \\ Presente do nosso Senhor \\ Amazônia do verde, Amazônia menina \\ Inspiração do poeta \\ Quando canta o uirapuru \\ No voo da garça morena \\ No ministério da Yara mãe d’água}

Amazônia

Amazônia, Amazônia

O homem precisa cuidar de você".

Do mesmo modo apresentaremos um outro fragmento musical da toada " A grande maloca" escrita por Demetrios Haidos e Geandro Pantoja, esta toada pertence ao Boi Garantido apresentada no ano de 2006, assim expressa:

“[...] Se a humanidade não cuida da grande maloca

A natureza dedilha tristes acordes

Clamores a ecoar pro mundo não se acabar

Na fúria do mar e dos ventos 
No gemido da terra e da selva

E na seca dos rios da Amazônia, a vida suplicará!

[...] Terra a grande maloca que devemos cuidar

Enquanto houver o amanhã.

Ao fazer uma breve análise de conteúdo das letras desses pequenos fragmentos musicais, podemos detectar inicialmente que se trata da Amazônia, assim, estão presentes alguns elementos da natureza em harmonia com seus mitos e lendas. Nesse sentido, os autores conclamam a sua preservação, expressam dizendo que a Amazônia precisa que o homem a trate com cuidado e ao tratá-la com respeito e cuidado, o próprio homem estará preservando para a presente e futuras gerações, o grande patrimônio natural que é a Amazônia.

Todos nós, homens e mulheres precisamos adotar a ética do cuidado para com a vida, respeitar e cuidar da natureza é um imperativo ético que devemos sempre utilizar em nossas práticas cotidiana de vida. "A ética do cuidado hoje é fundamental: se não cuidarmos do planeta Terra, ele poderá sofrer um grande colapso e destruir as condições que permitem o projeto planetário humano" (Boff, 2003).

As referidas letras musicais podem ser trabalhadas de modo interdisciplinar na EJA, pois seus conteúdos permeiam todas as áreas do conhecimento, facilitando 0 diálogo entre as diversas disciplinas curriculares. Assim, podemos concluir dizendo que as toadas do Boi-Bumbá de Parintins são verdadeiras aliadas no que tange ao despertar ecológico regional, nacional e mundial.

\section{CONSIDERAÇÕES FINAIS}

A Educação Ambiental na Educação de Jovens e Adultos é tão necessária para a formação da cidadania, pois tem o propósito de educar o homem para que se torne um sujeito autônomo, dono de seu quefazer e assim possa se inserir na sociedade globalizada de forma participativa. 


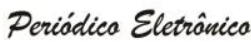 Fórum Ambiental}

da Alta Paulista

Volume 9, Número 6, 2013

Educação Ambiental

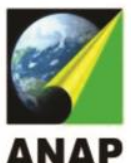

É possível dizer que apesar da EJA se configurar uma modalidade de ensino assegurada nos Artigos 37 e 38 da LDBNo 9.394/96, ainda há muito a ser feito, pois não basta só garantir 0 direito à educação, mas também assegurar 0 acesso e a permanência do aluno da EJA na escola.

Para isso, faz-se necessário a construção de escolas com infra-estrutura dotada de bibliotecas, laboratórios de informática, quadro poliesportiva, livros didáticos, auditórios e refeitórios.

No que tange a parte pedagógica são necessário investimentos na formação inicial e continuada de professores da educação de jovens e adultos, valorização e incentivo à pesquisa.

\section{REFERÊNCIAS}

AZEVEDO, Reinaldo. Depois de quinze anos, taxa de analfabetismo volta a crescer no Brasil. Disponível em <veja.abril.com.br>. Acesso em 14/10/2013.

BRANDÃO, Carlos Rodrigues. O que é método Paulo Freire. Disponível em < sitiorosadosventos.com.br>. Acesso em 09/10/2013.

BOFF, Leonardo. Ética e eco-espiritualismo. Campinas, SP: Verus Editora, 2003.

. 0 cuidado necessário: na vida, na saúde, na educação, na ecologia, na ética e na espiritualidade. Petropólis, RJ: Vozes, 2012.

CAPRICHOSO: A MAGIA QUE ENCANTA. À arte do audacioso. Parintins, 2011.

FAZENDA, Ivani. (Coord.) Práticas interdisciplinares na escola. 13. ed. rev.e ampl. São Paulo: Cortez,2013.

FREIRE, Paulo. Pedagogia da autonomia: saberes necessários à prática educativa. São Paulo, Paz e Terra,2011.

Pedagogia do oprimido. 50. ed . ver. atual. - Rio de Janeiro: Paz e Terra,2011.

GARANTIDO: TERRA A GRANDE MALOCA. A grande maloca. Parintins, 2006.

PARECER CNE/CEB/11/2000 SOBRE DIRETRIZES CURRICULARES NACIONAIS PARA EDUCAÇÃO DE JOVENS E ADULTOS. Disponível em www.mec.gov.br. Acesso em 14/10/2013. 
RESOLUÇÃO № 2, DE 15 DE JUNHO DE 2012. Diretrizes Curriculares Nacionais para a Educação Ambiental. Disponível em < www.mec.gov.br>. Acesso em 14/10/2013.

SOUZA, Paulo Nathanael Pereira de;SILVA, Eurides, Brito da. Como entender e aplicar a nova LDB: lei no 9.394/96. São Paulo: Pioneira,1997. 